\title{
Dietary nitrate: poison or panacea?
}

William Heberden wrote of poisons 'use and observation have taught us to make remedies of many of these substances and still more of them will be improved into such by posterity'. ${ }^{1}$ Until recently, nitric oxide fell firmly into the poisons camp, considered as an environmental pollutant or a toxic contaminant of cylinders of nitrous oxide that could cause cardiovascular collapse and death. However, with the discovery of the endogenous formation of nitric oxide from L-arginine ${ }^{2}$ and the identification of major physiological roles for this mediator, came a 'Kuhnian' leap in perception. In 1980 the idea that the body synthesised an inorganic gas and used it as a biological mediator might have seemed far fetched, but by 1990 there were nearly 1000 publications on the biology of nitric oxide and by 1996 the rate was in the order of 2000 papers a year. Three isoforms of nitric oxide synthase (NOS) have now been cloned and sequenced; the genes encoding the enzymes have been localised to human chromosomes 7 (eNOS), 12 (nNOS), and 17 (iNOS); knockout mice have been generated; polymorphisms of the genes have been identified, disease associations suggested, and new therapies proposed. ${ }^{3}$ But enzymatic activity might not always be necessary to generate nitric oxide. On page 211 , a study from Nigel Benjamin's group explores the chemical synthesis of nitric oxide in the human gastrointestinal system. The authors suggest that dietary nitrate, a substance implicated as an environmental carcinogen, and a bête noir of the agriculture commission of the European Community might have unexpected beneficial effects on human health.

Nitrate was identified as a constituent of saliva in $1890,{ }^{4}$ and salivary flow contributes more to our exposure to nitrite than any other source. However, pure ductal saliva contains nitrate but no nitrite, ${ }^{4}$ and the formation of nitrite in the mouth is dependent upon the presence of nitrate reductase in oral micro-organisms. ${ }^{+5}$ Independently, Lundberg $e t a l^{6}$ and Benjamin's group ${ }^{\top}$ suggested that the nitrite present in swallowed saliva is converted to nitric oxide in the acid environment of the stomach. Here, the toxic effects of nitric oxide (probably after combination with other radicals) seem to provide a more effective antimicrobial action than that provided by acid alone.

This is an intriguing pathway by which to synthesise nitric oxide, but where does the nitrate in saliva come from? In Rhodnius prolixis, a blood sucking bug, nitric oxide is generated within the salivary glands by the action of nitric oxide synthase. ${ }^{8}$ The bug injects nitric oxide bound to ferric iron into its prey to cause vasodilatation and inhibit platelet aggregation and thereby facilitate the ability to suck blood. It is possible that humans have retained nitric oxide synthase in salivary glands for other reasons and that some of the nitrate in saliva derives from this source. However, the experiments of $\mathrm{McKnight}$ et al clearly show that ingestion of nitrate in the diet increases the concentration of nitrate and nitrite in the saliva. This has been observed before and is consistent with studies demonstrating that the salivary glands transport and concentrate nitrate from the blood. It would be of interest to determine to what levels salivary nitrate concentrations would fall in subjects on a nitrate-free diet.

In keeping with earlier studies, no nitrite was detected in the acidified environment of the stomach. But the ingestion of nitrate in the diet was associated with a large increase in nitric oxide generation, suggesting that the swallowed nitrite has been converted to nitric oxide. Consistent with this suggestion, Lundberg et al showed that neutralisation of the stomach with a proton pump inhibitor decreased the chemical generation of nitric oxide. The results in the study of McKnight et al are less impressive in this respect. The neutral drink given to the volunteers caused no obvious change in the rate of change of nitric oxide generation, and it is perhaps surprising that nitrite did not appear in the stomach once the $\mathrm{pH}$ had increased. None the less, taken together the papers present a consistent picture. Nitric oxide is generated chemically within the stomach from swallowed nitrite derived from salivary nitrate, which in turn is extracted from the blood.

The research raises important questions. What is the function (if any) of the nitric oxide generated? Does it contribute to regulation of smooth muscle tone in the gut, or alter mucosal integrity, or is it an important host defence mechanism? Does the nitric oxide generated revert again to nitrate which is absorbed by the gut, or do other chemical reactions occur to generate nitric oxide adducts (for example, nitrosothiols) that might have biological (even systemic) activity in their own right? If the chemical generation of nitric oxide in the stomach has important host defence or other physiological effects, might dietary nitrate be beneficial and escape the stigma of nitrosamine formation with which it has long been associated? These are exciting possibilities that deserve further study. However, nitric oxide itself can cause damage to DNA and mutation in human cells in vitro, ${ }^{9}$ and the glimpses of therapeutic promise provided by the work of Benjamin's group will need to be weighed against possible hazards and explored carefully in toxicological and clinical studies.

Centre for Clinical Pharmacology and Therapeutics,

PATRICK VALLANCE University College, London WC1E $67 \mathcal{F}$

1 Heberden W. On the history, nature and cure of poisons. Royal College of Physicians, 1749.

2 Palmer RMJ, Ashton DS, Moncada S. Vascular endothelial cell synthesize nitric oxide from L-arginine. Nature 1988; 333: 664-6.

Moncada S, Higgs EA. Molecular mechanisms and therapeutic strategies related to nitric oxide. FASEB f 1995; 9: 1319-30.

4 Tannenbaum SR, Sisnkey AJ, Weisman M, Bishop W. Nitrite in human saliva. Its possible relationship to nitrosoamine formation. 7 Natl Cancer Inst 1974; 53: 79-84.

5 Sasaki T, Matano K. Formation of nitrite from nitrate at the dorsum linguae. F Food Hyg Soc fpn 1979; 20: 363-9.

6 Lundberg JO, Weitzberg E, Lundberg JM, Alving K. Intragastric nitric oxide production in humans: measurements in expelled air. Gut 1994; 35: 1543-6.

7 Benjamin N, O'Driscoll F, Dougall H, Duncan C, Smith L, Golden M, et al. Stomach NO synthesis. Nature 1994; 368: 502 .

8 Ribeiro JM, Hazzard JM, Nussenzveig RH, Champagne DE, Walker FA. Reversible binding of nitric oxide by a salivary heme protein for a Reversible binding of nitric oxide by a salivary heme protein for a
bloodsucking insect. Science 1993; 260: 539-41.

9 Nguyen T, Brunson D, Crespi CL, Penman BW, Wishnok JS, Tannenbaum SR. DNA damage and mutation in human cells exposed to nitric oxide in vitro. Proc Natl Acad Sci USA 1992; 89: 3030-4. 